\title{
The influence of ethical leadership on trust and work engagement: An exploratory study
}

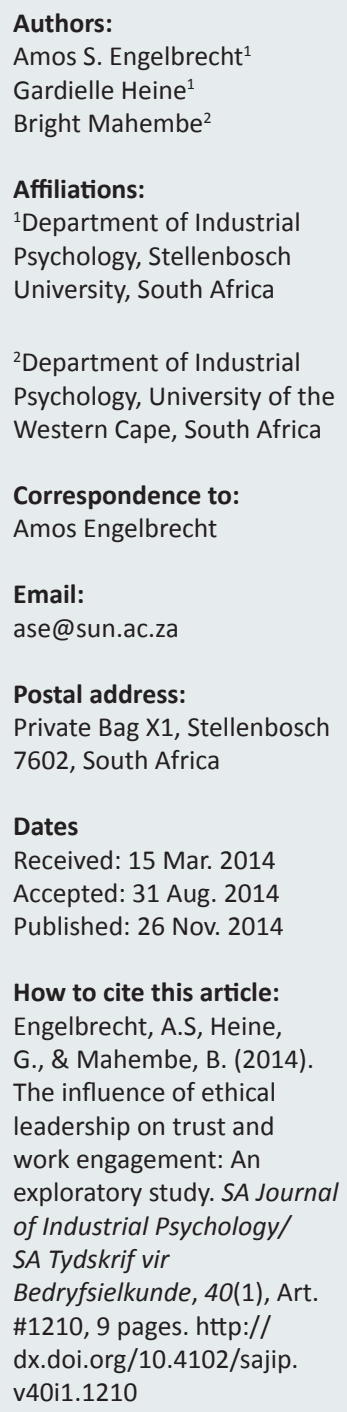

Orientation: Work engagement is increasingly becoming an important outcome for organisational success. A trusting and ethical relationship between leaders and followers is likely to positively contribute to the work engagement of employees.

Research purpose: The aim of the study was to investigate the relationship between ethical leadership and trust in the leader and the effect these constructs have on the work engagement of employees.

Motivation for the study: The study on the role of ethical leadership practices on employee engagement was motivated by the need to create an engaged workforce and a trusting work environment.

Research approach, design and method: Data was collected using an electronic web-based questionnaire comprising three scales, namely the Utrecht Work Engagement Scale (UWES), Leader Trust Scale (LTS) and the Leadership of Ethics Scale (LES). In total, 204 completed questionnaires were returned. Data was analysed by means of item and confirmatory factor analysis conducted via structural equation modelling (SEM).

Main findings: High levels of reliability were found for all the measurement scales used. The results from the structural equation modelling (SEM) indicated positive relationships between trust in the leader and work engagement, between ethical leadership and work engagement and between ethical leadership and trust in the leader.

Practical/managerial implications: The findings emphasise the role played by ethical leadership behaviour of managers in promoting work engagement through the creation of employee relationships anchored on trust. Future studies should develop the theoretical model further by identifying other variables that influence work engagement.

Contribution/value-add: Organisations today still face the challenge of developing an effective strategy for achieving work engagement. The ethical leadership style of managers is likely to create an ethical and trusting work climate conducive to the work engagement of employees. This is likely to enhance productivity as well as employee creativity and innovation.

\section{Introduction}

Organisations strive to be successful and productive in the competitive global market. One of the major factors or motivators of productivity and performance is work engagement (Bakker \& Demerouti, 2008; Den Hartog \& Belschak, 2012; Gruman \& Saks, 2011; Rich, Lepine \& Crawford, 2010; Tims, Bakker \& Xanthopoulou, 2011). According to Gruman and Saks (2011, p. 124), work engagement is the 'key to an organisation's success and competitiveness'. Employees will be productive and perform well in the company when they are really engaged in the work. This means that the employee enjoys the work, is committed to the work and is more efficient and involved in the work (Schaufeli \& Bakker, 2004).

Identifying the situations that foster the work engagement of employees is vital for the sustainability and growth of organisations (Lin, 2009). According to Lin (2009), one of the conditions that are critical in strengthening work engagement is organisational trust. Because employees are more likely to engage in their work if they are self-motivated to perform their role, trust on the part of management is essential. Excessive monitoring and enforcement from management can hamper employees' ability to engage in their work. The significance of interpersonal trust should therefore be acknowledged. Trust is a core element in the relationship between an organisational leader and subordinates, and it has an influence on how positively the employee will perceive the work environment.

How the leaders execute their leadership behaviour can influence the extent to which the followers will trust the leaders. Numerous value-based leadership styles such as transformational, authentic, servant 
and ethical leadership are linked with trust. Transformational leadership not only involves the moral elevation of individual followers, but also the creation of mutual trust and an ethical climate in organisations (Engelbrecht \& Chamberlain, 2005; Van Aswegen \& Engelbrecht, 2009). In ethical leadership, the emphasis is more on normative behaviour whereas servant leadership has a stronger focus on the personal growth of followers (Dadhich \& Bhal, 2008; Sendjaya \& Pekerti, 2010). The core aspects of authentic leadership are the manifestation of increased self-awareness, relational transparency, internalised transparency, balanced processing and an internalised moral perspective, which may lead to trust in leadership (Gardner, Avolio, Luthans, May \& Walumbwa, 2005). Value-driven leadership influences the followers' self-concept and beliefs, which, in turn, affect their motivation, attitudes and behaviours (Den Hartog \& Belschak, 2012).

One of the value-based leadership styles that comprise these elements is ethical leadership. Ethical leadership is critical to leaders' credibility and their potential to exert meaningful influence (Piccolo, Greenbaum, Den Hartog \& Folger, 2010). This credibility in ethical leaders is likely to have a significant influence on trust between a leader and follower (Bellingham, 2003). Ethical leadership leads to valuable outcomes in itself. It has an impact on organisational effectiveness by increasing top-management effectiveness, follower performance and job satisfaction (Eisenbeiß \& Giessber, 2012). Because ethical leadership affects the relationships in the organisation as well as other organisational outcomes, it is also likely to have a positive effect on the work engagement of employees.

\section{Aim of the study}

Work engagement is the driver behind an organisation's competitiveness and success, in that an engaged employee demonstrates the willingness to put extra effort into the work and to reach optimal performance. The importance of work engagement has to be emphasised in order to encourage organisations to invest in this valuable phenomenon as well as in the different elements that contribute to and enrich work engagement. Because the relationship between leaders and followers is so important in the company, trust and leadership are key aspects that should be considered in this case, especially when it can contribute to the presence of the work engagement of employees.

Ethical leadership is considered important because it promotes effective interaction between leaders and their followers by focusing on ethical behaviour in the workplace. According to Brown and Trevino (2006), ethical leaders are perceived as honest and trustworthy, which is necessary for healthy working relationships and may have a positive impact on work outcomes. The research objective of this study, therefore, was to make use of sound theoretical research and logical reasoning to analyse the influence of ethical leadership on trust in leaders and the work engagement of employees. The further aim was to validate a theoretical model that explicates the structural relationships between these variables in the South African business context.

\section{The relationship between trust and work engagement}

Work engagement is found when an employee is fully dedicated to the work through focused energy or vigour and a 'positive fulfilling, work related state of mind' or absorption (Schaufeli, Salanova, Gonzalez-Roma \& Bakker, 2002, p. 74). Work engagement, therefore, is an indication that the employee is intrigued by the job and is truly willing to contribute to the organisation's success (Albrecht, 2010).

Rousseau, Sitkin, Burt and Camerer (1998, p. 395) view trust as '... a psychological state comprising the intention to accept vulnerability based upon positive expectations of the intentions or behaviour of another'. When employees trust the leader, they expect that the leader will behave in a way that is favourable and acceptable to the employees and that the employees can entrust their work-life to the control of the leader.

When employees trust their leaders, they also assume the assurance that their leaders are fair in their behaviour and decisions. When the employees perceive the leaders as fair in the distribution of rewards and the treatment of their efforts, trust in the leaders will increase. Albrecht (2010) proposes that employees will engage in their work when the procedures and systems in the organisation are perceived as trustworthy, predictable and sensible.

In a study that was done on the effect that downsizing had on trust in an organisation, it was found that employees who experience an increase in trust also experience an increase in work engagement. The process that developed trust, therefore, contributed to higher levels of work engagement (Buckley, 2011). Wong, Spence-Laschinger and Cummings (2010) confirmed through their study that trust has a direct positive effect on work engagement $(\beta=0.19 ; p<0.001)$. They indicated that increased trust includes the free exchange of knowledge, ideas and information and that this trust will lead to a climate in which employees are engaged in their work. It can, therefore, be hypothesised that an employee's trust in a leader has a positive influence on the work engagement of employees.

\section{The relationship between ethical leadership and work engagement}

Employees will experience work engagement when they are committed to the work, enjoy the work and will go to extra trouble for the work. Macey, Schneider, Barbera and Young (2009) propose that work engagement results when employees have the capacity, the motivation, the freedom and the knowledge to engage. Ethical leadership presents different characteristics which can be associated with work engagement in terms of the line of reasoning of Macey et al. (2009).

Employees, firstly, have the capacity to engage when organisations provide the necessary information and training opportunities to do the job well, as well as a supporting structure which contributes to the employee's ability to 
perform (Macey et al., 2009). Ethical leaders provide certain job resources for the employees that assist them in the execution of their work such as effective performance feedback and necessary information to do the job. According to Bakker and Demerouti (2008), these resources are positively associated with work engagement because they provide employees with the necessary assistance to be exceptional in their jobs.

Secondly, employees will be motivated to engage in their work when they are treated with respect and are valued by the organisation (Macey et al., 2009). According to Kim and Brymer (2011), the behaviour of ethical leaders leads to the follower's work satisfaction because they are treated fairly and experience care and support, which leads to positive follower attitudes. Highly satisfied employees will be motivated and willing to apply extra effort because they are more committed to delivering high-quality work (Kim \& Brymer, 2011).

Thirdly, when an employee has the freedom to make decisions and take action without consulting the supervisor all the time, it can result in work engagement (Macey et al., 2009). Bellingham (2003) states that ethical leaders want to empower employees through training and support, and they want to provide freedom to their employees to show initiative through responsibility and authority. This provides a clear indication that ethical leaders provide the freedom for employees to engage in their work.

Lastly, as indicated by Macey et al. (2009), employees will engage in their work when they know what the strategic priorities of the organisation are and how they contribute to the company's goals through their work. Ethical leaders care about their followers and engage in frequent communication with their employees (Brown \& Trevino, 2006). These leaders take their followers into consideration and, through frequent communication, make it clear what the organisation's goals are and what is expected of them.

Tims et al. (2011) found a positive relationship between transformational leadership and the follower's daily work engagement $(t=2.33 ; p<0.05)$. They further refer to transformational leadership as practised by a leader with 'individual consideration and support' for the employee (Tims et al., 2011, p. 122). Wong et al. (2010) indicated the positive relationship between authentic leadership and work engagement. Both transformational and authentic leadership can be associated with ethical leadership because they are viewed as value-based leadership, which has a positive influence on the followers' work engagement.

Through regression analysis, Den Hartog and Belschak (2012) confirmed that ethical leadership has a positive relationship with work engagement $(\beta=0.54 ; p<0.01)$. They argue that the '... emphasis on shared moral values and the honesty, caring and fairness modelled by ethical leaders will foster employees' work engagement' (Den Hartog \& Belschak, 2012, p. 35). They found that followers tend to report higher engagement in their work when they perceive their leaders as acting ethically. It can consequently be hypothesised that ethical leadership has a positive influence on the employee's work engagement.

\section{The relationship between ethical leadership and trust in the leader}

An employee will trust a leader if the leader is trustworthy and if the leader displays characteristics of trustworthiness such as honesty, kindness, generosity and acceptance (Zeffane, 2010). Ethical leadership comprises different characteristics that are evident in the trust relationship between a leader and a follower.

According to Brown and Trevino (2006, p. 597), ethical leaders are characterised as '... honest, caring and principled individuals who make fair and balanced decisions'. They further indicate that such leaders communicate ethics to their employees and set clear standards regarding how things should be done in the organisation. Ethical leaders also have the courage to transform their moral intentions into ethical behaviour, which can be referred to as a high behavioural consistency (Zhu, May \& Avolio, 2004). When employees perceive this consistency, trust in the leader will result.

Ethical leadership involves employees in decision-making procedures and facilitates well-being and potential growth of the employees (Zhu et al., 2004). Employees will be inclined to trust ethical leaders because of their credibility and trustworthy behaviour. Dadhich and Bhal (2008) found that affective trust (the emotional bond between individuals) and cognitive trust (where trust is required in cases of imperfect knowledge) are predicted by ethical leadership. Van den Akker, Heres, Lasthuizen and Six (2009) found that ethical leadership is significantly related to the level of trust that the follower places in the leader.

Johnson, Shelton and Yates (2012) reported a positive relationship $(r=796 ; p<0.01)$ between ethical leadership and organisational trust. Wong et al. (2010) also found that authentic leadership has a positive direct effect on trust $(\beta=$ $0.43 ; p<0.001)$. Authentic leadership is displayed by leaders who strive to relate to their followers with openness and truthfulness. These characteristics are also part of ethical leadership, which indicates the possible positive influence of ethical leadership on trust.

When employees exhibit the willingness to trust the leader and when an ethical leader establishes a basis of trust, the employee will also be inclined to trust the work environment and the organisation. It can thus be hypothesised that ethical leadership leads to employees' trust in the leader.

\section{Conceptual model}

Based on the in-depth literature review and theoretical arguments presented above, a structural model was formulated, showing the postulated relationships between ethical leadership, trust and work engagement. Ethical leadership is portrayed as the independent or exogenous 
variable whilst trust in the leader and work engagement are presented as endogenous variables. The structural model, illustrated in Figure 1, reflects the various paths and links between the different constructs.

\section{Statistical hypotheses}

Hypothesis 1: The overarching substantive research hypothesis was interpreted to indicate that the structural model depicted in Figure 1 provides a perfect explanation of the manner in which ethical leadership influences the trust between the leader and the follower as well as the work engagement of the follower in the organisation. The substantive research hypothesis was translated into the following exact fit null hypothesis:

$$
\begin{aligned}
& \mathrm{H}_{01}: \mathrm{RMSEA}=0 \\
& \mathrm{H}_{\mathrm{a} 1}: \mathrm{RMSEA}>0
\end{aligned}
$$

Where RMSEA is the root mean square error of approximation.

Hypothesis 2: If the overarching substantive research hypothesis is interpreted to indicate that the structural model provides an approximate account of the way in which ethical leadership influences the trust between the leader and follower as well as the work engagement of employees, the substantive research hypothesis would translate into the following close fit null hypothesis:

$$
\begin{aligned}
& \mathrm{H}_{02}: \mathrm{RMSEA} \leq 0.05 \\
& \mathrm{H}_{\mathrm{a} 2}: \mathrm{RMSEA}>0.05
\end{aligned}
$$

The overarching substantive research hypothesis was divided into three more detailed, specific substantive research hypotheses. These three research hypotheses were converted into the following path-coefficient statistical hypotheses:

Hypothesis 3: Trust in the leader $\left(\eta_{1}\right)$ has a significantly positive influence on the follower's work engagement $\left(\eta_{2}\right)\left(\mathrm{H}_{03}: \beta_{21}=0\right.$; $\left.\mathrm{H}_{\mathrm{a} 3}: \beta_{21}>0\right)$.

Hypothesis 4: Ethical leadership $\left(\xi_{1}\right)$ has a significantly positive influence on the follower's work engagement $\left(\eta_{2}\right)\left(H_{04}: \gamma_{21}=0\right.$; $\left.\mathrm{H}_{\mathrm{a} 4}: \gamma_{21}>0\right)$.

Hypothesis 5: Ethical leadership $\left(\xi_{1}\right)$ has a significantly positive influence on trust in the leader $\left(\eta_{1}\right)\left(\mathrm{H}_{05}: \gamma_{11}=0 ; \mathrm{H}_{\mathrm{a} 5}: \gamma_{11}>0\right)$.

\section{Research design}

\section{Research approach}

The objectives set out for this research were achieved through the use of a cross-sectional correlational research design. A quantitative survey design was used to achieve the research objectives.

\section{Research method}

\section{Research participants}

This study made use of non-probability sampling as a way of obtaining the appropriate sample. The research hypotheses were empirically tested using a sample size of 204 respondents which consisted of employees operating within

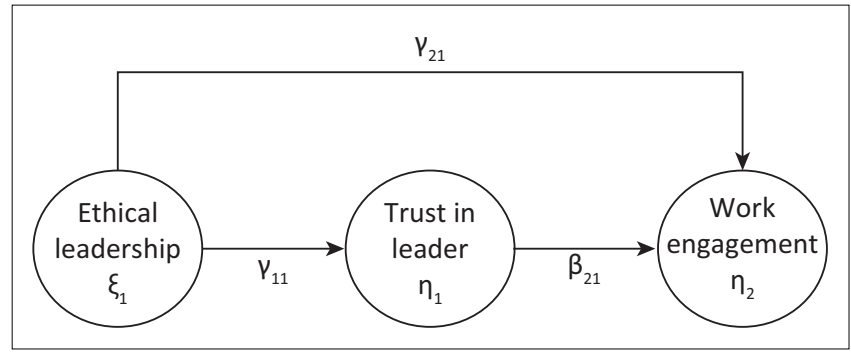

FIGURE 1: The structural model representing the relationships between ethical leadership, trust and work engagement.

various organisations in South Africa. The overall sample consisted of 81 male respondents $(37.9 \%)$ and 123 female respondents $(60.3 \%)$. The sample presented an average age of 37.53 years, which indicates that the majority of respondents were aged between 31 and 40 years. The race distribution of the sample was as follows: African respondents (5.4\%), mixedrace respondents (2\%), Indian respondents (34.8\%) and white respondents $(57.8 \%)$. The sample was furthermore compiled from respondents from different companies and industries. The majority of respondents came from middle-level management (58.3\%) and from the retail industry (80.4\%). The manufacturing $(9.8 \%)$ and financial $(7.4 \%)$ industries were also represented in the sample, but in smaller quantities.

A questionnaire designed to gather data was distributed through the Internet and was sent to the identified participants. Participants were required to accept the conditions specified in the instructions of the online version. Confidentiality was maintained by assuring participants that their responses would be treated as anonymous and no names would be revealed in the study. Respondents evaluated their own work engagement and the trust they have in their direct manager. They also assessed their manager's perceived ethical leadership.

\section{Measuring instruments}

Three measuring instruments were used to measure the constructs of ethical leadership, trust and work engagement.

\section{Work engagement}

Work engagement was measured by the original 17-item Utrecht Work Engagement Scale (UWES). The UWES, developed by Schaufeli and Bakker (2003), contains three dimensions of work engagement, namely vigour, dedication and absorption.

The UWES has demonstrated sound psychometric properties where the three-factor structure of the UWES fits well with the data of various samples and therefore confirms factorial validity. The three scales are highly internally consistent with Cronbach's alphas exceeding 0.7 (Schaufeli \& Bakker, 2003). Acceptable Cronbach's alpha coefficients of the scales were also found in South African studies (Rothmann, 2003).

\section{Trust in the leader}

Trust in the leader was measured by the 13-item Leader Trust Scale (LTS), developed for the purpose of this study. Eleven items of the LTS were adapted from the trust instrument 
by Bews (2000), and two items were adapted from the Workplace Trust Survey (WTS), developed by Ferres, Connell and Travaglione (2004).

\section{Ethical leadership}

Ethical leadership was measured by the 17-item Leadership of Ethics Scale (LES), which was developed for the purpose of this study. The LES was based on items from different measures of ethical leadership (Brown, Trevino \& Harrison 2005; Spangenberg \& Theron, 2005; Yukl, Mahsud, Hassan \& Prussia, 2011).

All 10 items of the Ethical Leadership Scale (ELS) developed by Brown et al. (2005) were included in the LES. The ELS combines different leadership behaviours such as acting fairly and honestly and rewarding ethical conduct.

Three items of the Ethical Leadership Inventory (ELI) (Spangenberg \& Theron, 2005) were integrated in the LES because they introduce the dimension of a vision and the transferring of ethical leadership into the organisation.

Four items from the Ethical Leadership Questionnaire (ELQ) (Yukl et al., 2011) were also included in the LES since they elaborate on the ethical practices of ethical leaders.

\section{Statistical analysis \\ Missing values}

Given the format of the online questionnaire that permitted participants to proceed only if the previous answer was filled out, missing values did not present a problem.

\section{Reliability analysis}

SPSS (Version 20) was used to perform an item analysis on all three measurement scales in order to ensure internal reliability and to identify the items that do not contribute to the internal description of the latent variables. After all of the scales were examined, it was concluded that all the Cronbach's alpha values exceed the required 0.7 cut-off (see Table 1) and all items present high item-total correlations. No items were consequently deleted. Each scale was, therefore, considered to be internally consistent and reliable.

\section{Evaluating the measurement models}

After internal consistency was confirmed on all scales, LISREL 8.80 (Jöreskog \& Sörbom, 2006) was used to perform confirmatory factor analysis (CFA), based on items as manifest variables, on all the scales and subscales used in this

TABLE 1: Reliability of the measurement scales.

\begin{tabular}{lll}
\hline Scale & Number of items & $\boldsymbol{\alpha}$ \\
\hline UWES: Absorption & 6 & .89 \\
UWES: Dedication & 5 & .91 \\
UWES: Vigour & 6 & .88 \\
LTS & 13 & .97 \\
LES & 17 & .97 \\
\hline
\end{tabular}

UWES, Utrecht Work Engagement Scale; LTS, Leader Trust Scale; LES, Leadership of Ethics Scale study. This was done in order to investigate the goodness-offit between the measurement models and the obtained data and to identify any poor items.

The initial results of the CFA are discussed per scale in terms of the $p$-value test of close fit (where $p>0.05$ indicates good model fit) and the root mean square error of approximation (RMSEA) (where RMSEA $<0.08$ indicates a reasonable model fit and RMSEA $<0.05$ indicates a good fit of the data) (Diamantopoulos \& Siguaw, 2000). If poor fit was found, the modification indices were investigated in order to determine the possibility of deleting items with lower loadings on the completely standardised solution matrix and increasing model fit. After deleting poor items, an additional CFA was performed on the refined scale.

From the UWES, a poor item from the absorption subscale and one from the vigour subscale were removed in order to increase the model fit. All items including in the Leader Trust Scale (LTS) loaded satisfactorily $(>0.5)$ on the latent variable. Three items of the Leadership of Ethics Scale (LES) were deleted because of their low factor loadings. The deletion of these items resulted in a substantial improvement in the fit indices.

\section{Goodness-of-fit: The refined UWES measurement models}

The final step in the analysis of the measurement models was to test the individual fit of each measurement model in terms of goodness-of-fit statistics that were obtained after the final CFA had been performed separately on the refined subscales of the UWES. The fit indices are represented in Table 2.

The fit indices indicate that the refined measurement models of absorption, dedication and vigour present acceptable fit with the data. Not enough evidence was found to reject the null hypothesis of exact fit. Thus, there was a possibility of an exact model fit with the data. The RMSEA, which indicates how well the model fits the covariance matrix, suggests that the refined measurement models fit the obtained data adequately (0.0-0.055) (Hair, Black, Babin, Anderson \& Tatham, 2006; Kelloway, 1998).

The $p$-value for test of close fit $($ RMSEA $<0.05)$ ranges from $0.38-0.69$, supporting the conclusion that the null hypothesis of close fit is not rejected $(p>0.05)$, and the various measurement models can be said to show close fit. An RMR of 0.03 was found, indicating a good fit (Hair et al., 2006). The standardised RMR is a more stable index to consider, and in this instance, the standardised RMR values are all below the 0.05 threshold, providing evidence of a relatively good model fit (Diamantopoulos \& Siguaw, 2000).

A positive picture is also expressed by the GFI. The GFI for each of the measurement models are close to 1 and above 0.9 . This indicates that good absolute fit has been achieved for each measurement model (Kelloway, 1998).

The results of the incremental fit indices indicate that all the measurement models achieved NFI, CFI and IFI indices that are $>0.9$, which represents good fit (Hair et al., 2006). These 
TABLE 2: Goodness-of-fit indices for all the scales and subscales.

\begin{tabular}{|c|c|c|c|c|c|c|c|c|c|c|}
\hline Model & S-B $\chi^{2}$ & $d f$ & RMSEA & $p_{\text {close fit }}$ & RMR & SRMR & GFI & NFI & CFI & IFI \\
\hline Absorption & 4.791 & 5 & 0.0 & 0.69 & 0.03 & 0.02 & 0.99 & 0.99 & 0.99 & 0.99 \\
\hline Dedication & 6.950 & 5 & 0.044 & 0.48 & 0.03 & 0.02 & 0.98 & 0.99 & 0.99 & 0.99 \\
\hline Vigour & 8.044 & 5 & 0.055 & 0.38 & 0.03 & 0.03 & 0.98 & 0.99 & 0.99 & 0.99 \\
\hline LTS & $124.865^{*}$ & 65 & 0.067 & 0.06 & 0.03 & 0.03 & 0.86 & 0.98 & 0.99 & 0.99 \\
\hline LES & $146.103^{*}$ & 77 & 0.067 & 0.05 & 0.04 & 0.04 & 0.87 & 0.98 & 0.99 & 0.99 \\
\hline SMODEL & 1097.759* & 699 & 0.053 & 0.20 & 0.05 & 0.046 & 0.74 & 0.97 & 0.99 & 0.99 \\
\hline
\end{tabular}

Note: S-B $\chi^{2}$, Sattora-Bentler Scaled Chi-square; $d f$, degrees of freedom; RMSEA, root mean square error of approximation; Pclose fit, $P$-Value for test of close fit (RMSEA < 0.05 ); RMR, root mean square residual; SRMR, standardised root mean residual; GFI, goodness-of-fit index; NFI, normed fit index; CFI, comparative fit index; IFI, incremental fit index; LTS, Leader Trust Scale; LES, Leadership of Ethics Scale; SMODEL, structural model

$*, \mathrm{p}<0.05$

comparative indices, therefore, appear to reveal a positive picture of model fit.

\section{Goodness-of-fit: The LTS measurement model}

The goodness-of-fit statistics for the LTS measurement model are indicated in Table 2. The reported indices indicate that satisfactory measurement model fit has been achieved. The null hypothesis of exact fit is rejected $(p<0.001)$. However, the $p$-value test of close fit (0.06) achieved a value that is indicative of close fit. The null hypothesis of close fit is, therefore, not rejected. The RMSEA (0.067) is also indicative of reasonable good fit.

The RMR value of 0.03 and the standardised RMR value of 0.03 are all below 0.05 , which indicates good fit. The GFI failed to exceed 0.9 but still reached a satisfactory value close to 1 , which indicates that the model comes close to reproducing the sample covariance matrix.

All the incremental fit indices presented in Table 2 exceeded the critical value of 0.9 , and therefore, the model indicates good comparative fit.

\section{Goodness-of-fit: The refined LES measurement model}

The goodness-of-fit statistics for the Leadership of Ethics Scale (LES) measurement model are indicated in Table 2. The reported indices indicated that satisfactory measurement model fit has been achieved after the refinement of the model. The null hypothesis of exact fit is rejected $(p<0.001)$, and the RMSEA (0.067) and $p$-value test of close fit (0.052) indicate close fit. The null hypothesis of close fit is, therefore, not rejected. The RMR and Standardised RMR expressed a positive picture with values $<0.05$, which indicates good fit. The GFI failed to exceed 0.90 but still reached a satisfactory value close to 1 , which indicates that the model comes close to reproducing the sample covariance matrix.

The results of the incremental fit measures indicate that the measurement model achieved NFI, CFI and IFI indices exceeding the critical value of 0.9 . These relative or comparative indices, therefore, appear to portray a positive depiction of model fit. The results seem to indicate that the model can be ascribed to more than chance.

\section{Goodness-of-fit indices for the structural model}

After it was found that the overall measurement model fitted the data reasonably well (RMSEA $=0.05$; Standardised
$\mathrm{RMR}=0.05 ; \mathrm{NFI}=0.97$ ), a CFA, based on items as manifest variables, was performed to evaluate the structural model. This was done to investigate the goodness-of-fit between the structural model and the data.

A thorough interpretation of all the fit indices led to the conclusion that the structural model fitted the data well. A summary of the most important fit indices is presented in Table 2. The Satorra-Bentler Scaled Chi-Square of 1097.759 ( $p<$ 0.01) indicates that the null hypothesis of exact fit (Hypothesis 1) can be rejected. The RMSEA value of this model (0.053) presents reasonable good fit. The $p$-value for test of close fit (0.2) indicates that the null hypothesis of close fit (Hypothesis 2) cannot be rejected, and therefore, the structural model shows close fit. The root mean square residual (RMR) of the structural model is found to be 0.0526. According to Kelloway (1998), LISREL provides the standardised RMR, which is a better index and indicates that values lower than 0.05 represents good fit. The standardised RMR value of this structural model is 0.046 , which indicates a reasonably good fit.

The goodness-of-fit index (GFI) (0.74) of this model did not achieve the ideal value of 0.90 . However, generally reasonable absolute fit has been achieved from the structural model.

The incremental fit indices, namely the NFI (0.97), CFI (0.99) and IFI (0.99), are above 0.90, which indicate good comparative fit relative to the independence model.

It was found that the structural model explained $79 \%\left(R^{2}=\right.$ $0.792)$ of the variance in trust in the leader and $39 \%\left(R^{2}=\right.$ 0.387) in work engagement.

To ensure a thorough assessment of the structural model, it was also necessary to investigate the modification indices to determine the extent to which the model explained the observed covariance amongst the manifest variables. Examination of the modification indices suggested that there were no additional paths between any latent variables that would substantially improve the fit of the proposed structural model. These results, therefore, indicated that the structural model was successful to the extent that it explained the observed covariance amongst the apparent variables.

\section{Discussion}

An examination of the theoretical links was necessary to determine whether these relationships specified at the 
conceptualisation stage were supported by the data. Further assessment on the structural model was therefore conducted to establish the significance of these empirical relationships between the various constructs.

\section{The relationship between trust and work engagement}

A positive relationship between trust in the leader and the work engagement of the employee was confirmed through the statistical techniques $(t=2.47 ; p<0.05)$ (see Table 3$)$. The SEM results revealed significant path coefficients between these two constructs, which led to the rejection of the null hypothesis $\left(\mathrm{H}_{03}: \beta_{21}=0\right)$. The finding is consistent with the results obtained in the literature (Albrecht, 2010; Buckley, 2011; Wong et al., 2010).

The results support the study by Wong et al. (2010), which found that a climate in which employees are engaged in their work can be created through the trustworthy behaviour of the leader and the confidence the follower displays in the leader. Albrecht (2010) emphasised the increase in work engagement when the employee trusts the leader to be fair in the distribution of outcomes and in systematic procedures.

If employees trust their leader, they assume that the leader will make decisions with the employees' best interest in mind, and the employees will be more willing to engage in their jobs because they know that their work-life is in good hands (Buckley, 2011).

It was confirmed in the present study that a relationship expressive of trust in the leader will promote the presence of work engagement in employees. The employees will be driven and committed to the work on the basis of the trust that they have in the leader to make informed and fair decisions regarding work.

\section{The relationship between ethical leadership and work engagement}

Support was found in the present study for a positive relationship between ethical leadership $\left(\xi_{1}\right)$ and followers' work engagement $\left(\eta_{2}\right)(t=2.27 ; p<0.05)$ (see Table 3). Through SEM, this path was found to be significant in the model. This subsequently led to the confirmation of Hypothesis $4\left(\mathrm{H}_{\mathrm{a} 4}\right.$ : $\left.\gamma_{21}>0\right)$.

This result offers support to similar research findings in the literature (Den Hartog \& Belschak, 2012; Macey et al., 2009; Tims et al., 2011; Wong et al., 2010). The positive relationship supports the work of Den Hartog and Belschak (2012) who found that employees, who perceived their leaders as acting ethically, tend to report improved engagement in terms of feeling more vigorous, dedicated and absorptive at work. It was also found that transformational, authentic and ethical leadership are positively related to work engagement because they all have the main drive of value-based leadership (Den Hartog \& Belschak, 2012; Tims et al., 2011; Wong et al., 2010).
TABLE 3: The gamma and beta matrix of path coefficients for the structural model.

\begin{tabular}{lll}
\hline Latent variable & Ethical leadership & Trust \\
\hline Trust & 0.89 & - \\
& $(0.07)$ & - \\
& $12.49 *$ & - \\
Work engagement & 0.30 & 0.34 \\
& $(0.13)$ & $(0.14)$ \\
& $2.27^{*}$ & $2.47^{*}$ \\
\hline
\end{tabular}

Completely standardised path coefficients in bold.

Standard error estimates in brackets

$t$-values $\geq|1.96|$ indicate significant parameter estimates

$*, p<0.05$

It emphasises the fact that followers are highly engaged in their work when they perceive their leaders as acting ethically.

Macey et al. (2009) propose that work engagement results when ethical leaders facilitate employees to have the capacity, the motivation, the freedom and the knowledge to engage in their work. Leaders who promote ethical behaviour empower employees by providing them with the necessary opportunities to become capable in executing their jobs. Ethical leaders treat employees equally and promote fair and principled decision-making. They communicate openly to their followers about goals and expectations (Brown \& Trevino, 2006). Ethical leaders inspire employees through an ethical vision and provide the freedom for employees to take initiative in the workplace. This kind of behaviour in an ethical leader provides the environment and the opportunity for employees to be fully engaged in their work.

\section{The relationship between ethical leadership and trust}

The hypothesised relationship between ethical leadership $\left(\xi_{1}\right)$ and trust in the leader $\left(\eta_{1}\right)$ has been confirmed in this study, which resulted in the rejection of the null hypothesis $\left(\mathrm{H}_{05}: \gamma_{11}=0\right)(t=12.49 ; p<0.05)$ (see Table 3$)$. The positive relationship between these two latent variables is also well documented in the literature (Brown \& Trevino, 2006; Dadhich \& Bhal, 2008; Johnson et al., 2012; Van den Akker et al., 2009; Wong et al., 2010; Zeffane, 2010).

The degree to which leaders are perceived as trustworthy will influence the way in which followers place their confidence, trust and belief in the leaders. Ethical leadership is linked to trust because of the value-driven behaviour it promotes. A leader who values ethics and manages ethics in the workplace is likely to display honesty, fairness and care towards the employees (Brown \& Trevino, 2006). An ethical leader is also dedicated to open communication and to involving others in decisions. These characteristics of ethical leadership are concurrent with leaders that are trusted by their followers.

As with authentic leadership that has been shown to have a significantly positive effect on trust (Wong et al., 2010), ethical leadership also strives to relate to followers with openness and truthfulness. When employees perceive their leader as someone with concern for ethical behaviour and who will 
take employees' needs into consideration when important decisions are made, they will be likely to display sincere trust in the leader. Thus, the positive relationship between ethical leadership and trust that was found in this study contributes to similar findings by various researchers in the field of organisational leadership.

\section{Limitations of the study and suggestions for future research}

Although the study offers valuable insight about important constructs of leadership and work engagement, some limitations need to be considered for the purpose of providing information on how future studies can be improved and extended. This study was firstly guided by an interest in employees' perceptions of the leader and how this related to their own outcomes. It was thus a single-source study and attention was not given to other sources. Multiple sources of data such as leaders' self-assessment of their own ethical leadership and peer ratings could be considered in future studies. Avey, Wernsing and Palanski (2012) also refer to the level of congruence between self and follower assessments, which can be utilised to obtain multi-source data.

Secondly, this study represents an attempt to explain specific relationships between the concerned variables in order to gain a better understanding of this complex network. It is, however, impossible to determine the exact scope of impact of these relationships and to include all the elements of the nomological network that may influence ethical leadership and work engagement. Future studies could explore other variables which may have an effect on these constructs, as well as other mediating and moderating variables, to clarify the relationship between ethical leadership and work engagement (e.g. organisational justice, ethical values, psychological empowerment and ethical climate). It is also suggested that a longitudinal study of the proposed conceptual model be executed to enable more substantial causal inferences.

A third limitation concerns the sampling method that was used. The non-probability sampling procedure may have reduced the ability to generalise the results of the study. It is suggested, therefore, that, when selecting respondents, future studies should avoid making use of a convenient sample but should make use of a sample that is chosen on the basis of greater probability and randomness.

A fourth limitation entails that the ethical leadership construct may be multidimensional (Spangenberg \& Theron, 2005). In this study, it was found that the LES is uni-dimensional. It is, therefore, recommended that the LES be further refined to capture a broader domain of ethical leadership.

The last limitation involves the statistical power of testing a covariance structure model using RMSEA. It is suggested that a minimum sample size should be used to achieve a given level of power (MacCallum, Browne \& Sugawara, 1996). Some evidence regarding a lack of adequate power to carry out planned hypothesis testing was found in the present study. A recommendation for future studies is to determine the minimum sample size required to achieve a given level of power and to ensure that sample size meets that criterion.

\section{Managerial implications}

With respect to work engagement, the present framework of the relationship between work engagement and trust in the leader is of help in identifying leadership practices that promote the development of work engagement. Managers should, therefore, put various mechanisms in place to promote the work engagement of employees. Bakker and Demerouti (2008) suggest that an important startingpoint for the promotion of work engagement is to measure work engagement and its drivers amongst all employees in the organisation. Interventions should then be aimed at striving to constitute work engagement at an individual and organisational level. Some of the practical methods that management could use are different motivating resources such as support and recognition by colleagues and supervisors. Successful performance feedback, with the focus falling on work engagement, could help to create high levels of engagement (Gruman \& Saks, 2011). Opportunities for learning, development and the utilising of skills in own jobs are also options in promoting the work engagement of employees.

Trust between leaders and followers are critical for the creation of a trustful work environment and an engaged workforce, and management could thus implement a variety of organisational programmes to strengthen trust in the company. Practical means of improving the trust between management and employees could range from the promotion of open information sharing to the development and empowerment of employees. Management could also implement and articulate an appealing vision that promotes social justice and morality. It would be important, however, to acknowledge the immense impact of the managers' actions that determine their trustworthiness and, therefore, their influence on the trust the employee has in managers.

As confirmed through this study, mutual trust and the work engagement of employees will be strengthened by ethical leadership in the work environment. Practical guidelines would suggest leading through ethical role modelling, developing performance criteria that reward ethical behaviour, facilitating fair and ethical solutions to problems and conflict, monitoring fraud and corruption through internal and external audit systems and promoting a code of ethical conduct (Yukl, 2013).

\section{Conclusion}

Organisations should take full responsibility for ensuring that ethical leaders drive management practices and that trust in the leaders is developed through the presence of ethically based business systems and functions. By strengthening these 
factors, work engagement is promoted amongst employees because of the trust they have in their leaders for taking their interests into consideration and for behaving in a fair and ethical manner when decisions are made in a turbulent work environment.

\section{Acknowledgements}

\section{Competing interests}

The authors declare that they have no financial or personal relationship(s) that may have inappropriately influenced them when they wrote this article.

\section{Authors' contributions}

A.S.E (Stellenbosch University) was the project leader responsible for initiating the conceptualisation of the study, for developing the LTS and LES and for writing the article. G.H. (Stellenbosch University) collected the data and was also responsible for the refinement of the measures and the write-up of the article. B.M. (University of the Western Cape) helped with the statistical analyses and interpretation of the results.

\section{References}

Albrecht, S.L. (2010). Handbook of employment engagement: Perspectives, issues, research and practice. London: Edward Elgar. http://dx.doi.org/10.4337/ 9781849806374

Avey, J.B., Wernsing, T.S., \& Palanski, M.E. (2012). Exploring the process of ethical leadership: The mediating role of employee voice and psychological ownership. Journal of Business Ethics, 107, 21-34. http://dx.doi.org/10.1007/s10551-012 1298-2

Bakker, A.B., \& Demerouti, E. (2008). Towards a model of work engagement Career Development International, 13(3), 209-223. http://dx.doi.org/10.1108/ 13620430810870476

Bellingham, R. (2003). Ethical leadership: Rebuilding trust in corporations. Amherst: HRD Press.

Bews, N.F. (2000). An investigation into the facilitators of the trustworthiness of managers. Unpublished doctoral thesis, Rand Afrikaans University, Johannesburg.

Brown, M.E., \& Trevino, L.K. (2006). Ethical leadership: A review and future directions. The Leadership Quarterly, 17, 595-616. http://dx.doi.org/10.1016/j. leaqua.2006.10.004

Brown, M.E., Trevino, L.K., \& Harrison, D. (2005). Ethical leadership: A social learning perspective for construct development and testing. Organisational Behaviour and Human Decision Processes, 97, 117-134. http://dx.doi.org/10.1016/j. obhdp.2005.03.002

Buckley, F. (2011). Trust and engagement in a downsizing context: The impact on human resource managers. In R.H. Searle \& D. Skinner (Eds.), Trust and human resource management (1st edn., pp. 309-329). London: Edward Elgar. http:// dx.doi.org/10.4337/9780857932006.00028

Dadhich, A., \& Bhal, K.T. (2008). Ethical leader behaviour and leader-member exchange as predictors of subordinate behaviours. VIKALPA, 33(4), 15-25.

Den Hartog, D.N., \& Belschak, F.D. (2012). Work engagement and Machiavellianism in the ethical leadership process. Journal of Business Ethics, 107, 35-47. http:// dx.doi.org/10.1007/s10551-012-1296-4

Diamantopoulos, A., \& Siguaw, J.A. (2000). Introducing LISREL: A guide for the uninitiated. London: Sage.

Eisenbeiß, S.A., \& Giessber, S.R. (2012). The emergence and maintenance of ethical leadership in organizations: A question of embeddedness? Journal of Personnel Psychology, 11(1), 7-19. http://dx.doi.org/10.1027/1866-5888/a000055

Engelbrecht, A.S., \& Chamberlain, L. (2005). The influence of transformational leadership on organisational citizenship behaviour through justice and trust. Management Dynamics, 14(1), 2-13.

Ferres, N., Connell. J., \& Travaglione, A. (2004). Co-worker trust as a social catalys for constructive employees attitudes. Journal of Managerial Psychology, 19(6), 608-622. http://dx.doi.org/10.1108/02683940410551516
Gardner, W.L., Avolio, B.J., Luthans, F., May, D.R., \& Walumbwa, F. (2005). Can you see the real me?: A self-based model of authentic leader and follower development. The Leadership Quarterly, 16, 343-372. http://dx.doi.org/10.1016/j.leaqua. The Leadership
2005.03.003

Gruman, J.A., \& Saks, A.M. (2011). Performance management and employee engagement. Human Resource Management Review, 21, 123-136. http://dx.doi. org/10.1016/j.hrmr.2010.09.004

Hair, J.F., Black, W.C., Babin, B.J., Anderson, R.E., \& Tatham, R.L. (2006). Multivariate data analysis (6th edn.). Upper Saddle River, NJ: Prentice Hall.

Johnson, C.E., Shelton, P.M., \& Yates, L. (2012). Nice guys (and gals) finish first: Ethical leadership and organizational trust, satisfaction and effectiveness. Internationa Leadership Journal, 4(1), 3-19.

Jöreskog, K.G. \& Sörbom, D. (2006). LISREL 8: User's reference guide. Chicago: Scientific Software International, Inc.

Kelloway, E.K. (1998). Using LISREL for structural equation modeling: A researcher's guide. New York: SAGE.

Kim, W.G. \& Brymer, R.A. (2011). The effects of ethical leadership on manager job satisfaction, commitment, behavioural outcomes, and firm performance. International Journal of Hospitality Management, 30, 1020-1026. http://dx.doi. org/10.1016/j.ijhm.2011.03.008

Lin, C. (2009). Modeling corporate citizenship, organizational trust, and work engagement based on attachment theory. Journal of Business Ethics, 94, 517-531. http://dx.doi.org/10.1007/s10551-009-0279-6

MacCallum, R.C., Browne, M.B., \& Sugawara, H.M. (1996). Power analysis and determination of sampling size for covariance structure modeling. Psychological Methods, 1(2), 130-149. http://dx.doi.org/10.1037/1082-989X.1.2.130

Macey, W.H., Schneider, B., Barbera, K.M., \& Young, S.A. (2009). Employee engagement: Tools for analysis, practice and competitive advantage. London Wiley-Blackwell. http://dx.doi.org/10.1002/9781444306538

Piccolo, R.F., Greenbaum, R., Den Hartog, D.N., \& Folger, R. (2010). The relationship between ethical leadership and core job characteristics. Journal of Organizational Behavior, 31, 259-278. http://dx.doi.org/10.1002/job.627

Rich, B.L., Lepine, J.A., \& Crawford, E.R. (2010). Job engagement: Antecedents and effects on job performance. Academy of Management Journal, 53 (3), 617-635. http://dx.doi.org/10.5465/AMJ.2010.51468988

Rothmann, S. (2003). Burnout and engagement: A South African perspective. SA Journal of Industrial Psychology, 29(4), 16-25. http://dx.doi.org/10.4102/sajip. v29i4.121

Rousseau, D.M., Sitkin, S.B., Burt, R.S., \& Camerer, C. (1998). Not so different after all: A cross-discipline view of trust. Academy of Management Review, 23(3), 393-404. http://dx.doi.org/10.5465/AMR.1998.926617

Schaufeli, W., \& Bakker, A. (2003). Utrecht Work Engagement Scale preliminary manual. Occupational Health Psychology Unit, Utrecht University.

Schaufeli, W.B., \& Bakker, A.B. (2004). Job demands, job resources, and their relationship with burnout and engagement: A multi-sample study. Journal of Organizational Behavior, 25, 293-315. http://dx.doi.org/10.1002/job.248

Schaufeli, W.B., Salanova, M., Gonzalez-Roma, V., \& Bakker, A.B. (2002). The measurement of engagement and burnout: A two-sample confirmatory factor analytic approach. Journal of Happiness Studies, 3, 71-92. http://dx.doi. org/10.1023/A:1015630930326

Sendjaya, S. \& Pekerti, A. (2010). Servant leadership as antecedent of trust in organizations. Leadership and Organization Development Journal, 31(7), 643-663. organizations. Leadership and Organization Deve
http://dx.doi.org/10.1108/01437731011079673

Spangenberg, H., \& Theron, C.C. (2005). Promoting ethical follower behaviour through leadership of ethics: The development of the ethical leadership inventory (ELI). South African Journal of Business Management, 36(2), 1-18.

Tims, M., Bakker, A.B., \& Xanthopoulou, D. (2011). Do transformational leaders enhance their followers' daily work engagement? The Leadership Quarterly, 22 121-131. http://dx.doi.org/10.1016/j.leaqua.2010.12.011

Van Aswegen, A.S., \& Engelbrecht, A.S. (2009). The relationship between transformational leadership, integrity and an ethical climate in organisations. $S A$ Journal of Human Resource Management, 7(1), 221-229.

Van den Akker, L., Heres, L., Lasthuizen, K., \& Six, F. (2009). Ethical leadership and trust: It's all about meeting expectations. International Journal of Leadership Studies, 5(2), 102-122.

Wong, C.A., Spence-Laschinger, H.K., \& Cummings, G.G. (2010). Authentic leadership and nurses' voice behaviour and perceptions of care quality. Journal of Nursing Management, 18, 889-900. http://dx.doi.org/10.1111/j.1365-2834.2010.01113.x

Yukl, G. (2013). Leadership in organizations. Upper Saddle River, NJ: Pearson. http:// dx.doi.org/10.1177/1548051811429352

Yukl, G., Mahsud, R., Hassan, S., \& Prussia, G.E. (2011). An improved measure of ethical leadership. Journal of Leadership and Organizational Studies, 20(10), 1-11.

Zeffane, R. (2010). Towards a two-factor theory of interpersonal trust: A focus on trust in leadership. International Journal of Commerce and Management, 20(3), 246-257. http://dx.doi.org/10.1108/10569211011076938

Zhu, W., May, D.R., \& Avolio, B.J. (2004). The impact of ethical leadership behaviour on employee outcomes: The role of psychological empowerment and authenticity. Journal of Leadership and Organizational Studies, 11(1), 16-26. http://dx.doi. org $/ 10.1177 / 107179190401100104$ 